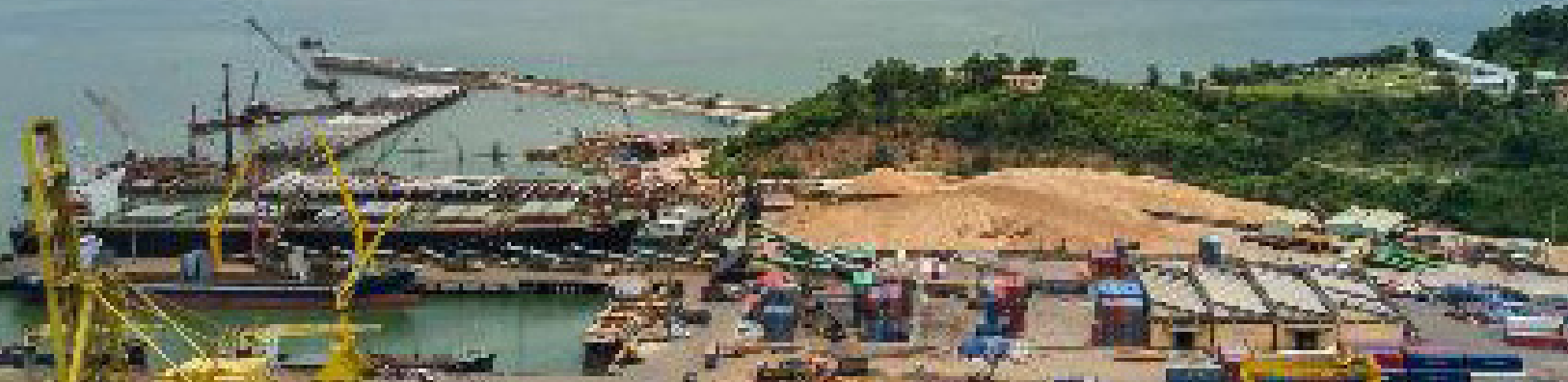

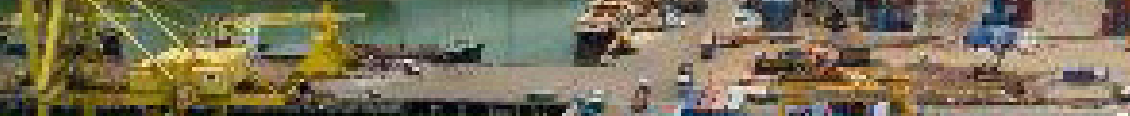

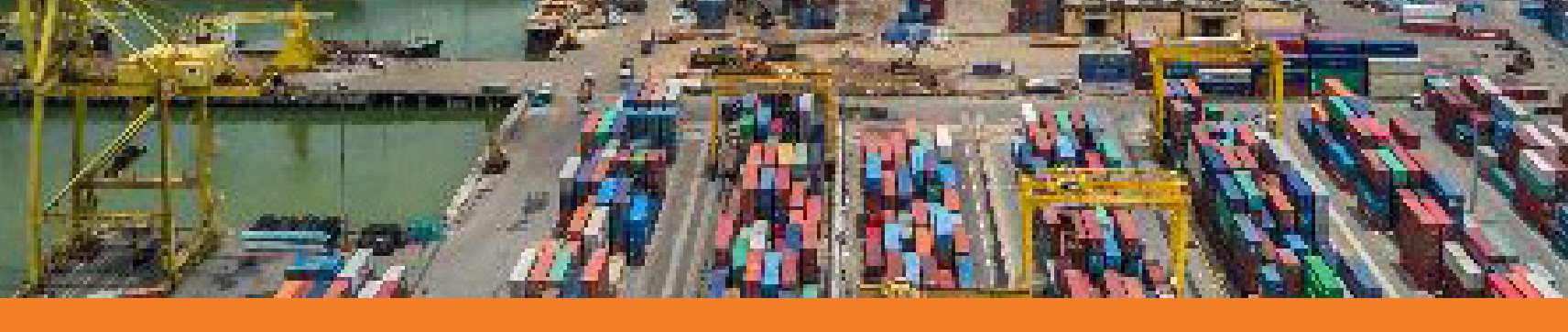

\title{
UNDERSTANDING DISASTER
}

RISK FOR ADVANCING

RESILIENT DEVELOPMENT

KNOWLEDGE NOTE

SEPTEMBER 2018 



\section{UNDERSTANDING DISASTER RISK FOR ADVANCING RESILIENT DEVELOPMENT KNOWLEDGE NOTE \\ SEPTEMBER 2018}


(C) 2018 Asian Development Bank 6 ADB Avenue, Mandaluyong City, 1550 Metro Manila, Philippines

Tel +632632 4444; Fax +6326362444

www.adb.org

Some rights reserved. Published in 2018

ISBN 978-92-9261-316-7 (print), 978-92-9261-317-4 (electronic)

Publication Stock No. TIM189534-2

DOI: http://dx.doi.org/10.22617/TIM189534-2

The views expressed in this publication are those of the authors and do not necessarily reflect the views and policies of the Asian Development Bank (ADB) or its Board of Governors or the governments they represent.

ADB does not guarantee the accuracy of the data included in this publication and accepts no responsibility for any consequence of their use. The mention of specific companies or products of manufacturers does not imply that they are endorsed or recommended by ADB in preference to others of a similar nature that are not mentioned.

By making any designation of or reference to a particular territory or geographic area, or by using the term "country" in this document, $A D B$ does not intend to make any judgments as to the legal or other status of any territory or area.

This work is available under the Creative Commons Attribution 3.0 IGO license (CC BY 3.0 IGO) https://creativecommons.org/licenses/by/3.0/igo/. By using the content of this publication, you agree to be bound by the terms of this license. For attribution, translations, adaptations, and permissions, please read the provisions and terms of use at https://www.adb.org/terms-use\#openaccess

This CC license does not apply to non-ADB copyright materials in this publication. If the material is attributed to another source, please contact the copyright owner or publisher of that source for permission to reproduce it. ADB cannot be held liable for any claims that arise as a result of your use of the material.

Please contact pubsmarketing@adb.org if you have questions or comments with respect to content, or if you wish to obtain copyright permission for your intended use that does not fall within these terms, or for permission to use the ADB logo.

Notes:

In this publication, "\$" refers to US dollars.

Corrigenda to ADB publications may be found at http://www.adb.org/publications/corrigenda

Photos on the front cover: Aerial view of Da Nang Port, Viet Nam.

All photos are from ADB unless otherwise stated. 


\section{ACKNOWLEDGMENTS}

This knowledge note was prepared under the Asian Development Bank (ADB) regional technical assistance project Enhanced Use of Disaster Risk Information for Decision Making in Southeast Asia. The project is financed by the Government of Canada through the ADB-administered Integrated Disaster Risk Management Fund. The note was prepared by Arghya Sinha Roy, senior disaster risk management specialist, Sustainable Development and Climate Change Department (SDCC) with technical inputs from Charlotte Benson, principal disaster risk management specialist, SDCC; and Noralene Uy, consultant. The note benefited from the inputs provided by various ADB staff during project implementation, including Eri Honda, principal urban development specialist, Southeast Asia Department (SERD); Kyaw Thu, infrastructure specialist, SERD; Soudalay Souannavong, associate project officer, SERD; and Chanthou Hem, senior project officer, SERD, and activities implemented by the United Nations Development Programme. The manuscript was edited by Cezar Tigno. The infographic and layout were designed by Lowil Espada. 



\section{INTRODUCTION}

Government officials involved in public investment planning, including officials from ministries of planning, and planning units of line agencies and local government are increasingly being called upon to undertake resilient development, in support of efforts to achieve the Sustainable Development Goals (SDGs). Disaster risk management (DRM) is an important aspect of resilient development and should be factored in all stages of the public investment planning process. In doing so, however, the role of public investment planners should not be limited to being passive users of disaster risk information, but instead be at the center in defining their risk information-related needs and supporting the development of such information in close partnership with hydrometeorological and geological institutes and relevant national agencies that address DRM and climate change.

This knowledge note is based on lessons learned from Southeast Asian countries, largely drawn from the Asian Development Bank (ADB) regional technical assistance project on Enhanced Use of Disaster Risk Information for Decision Making in Southeast Asia. The project was supported by the Integrated Disaster Risk Management Fund, administered by ADB and funded by the Government of Canada. The knowledge note provides guidance to government officials involved in public investment planning on increasing their engagement in understanding disaster risk. Such engagement is crucial if the SDGs are to be achieved.

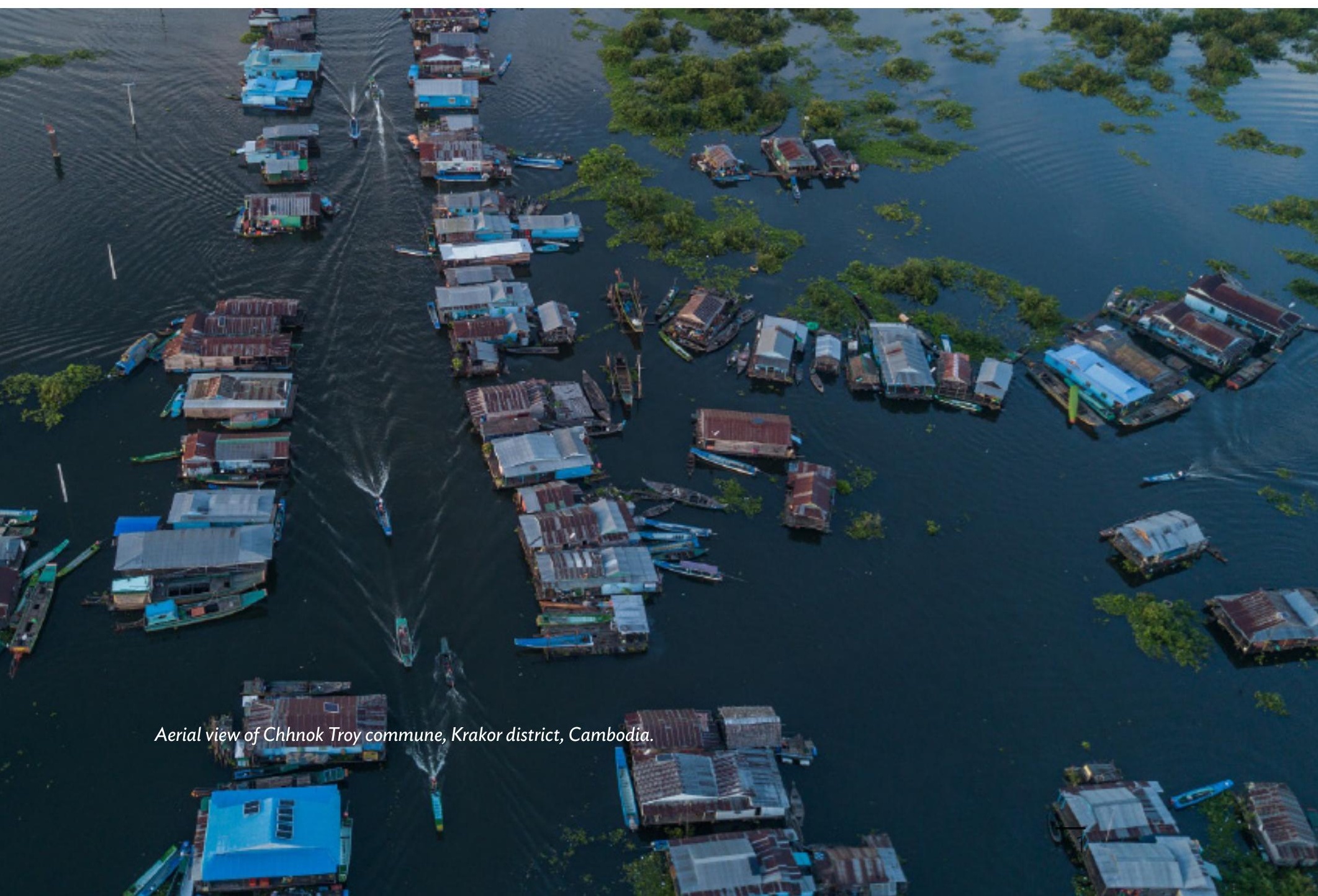




\section{DISASTER RISK-INFORMED PUBLIC INVESTMENTS IN SOUTHEAST ASIA}

\section{Disaster risk poses a serious challenge in achieving the sustainable development goals.}

In the last 3 decades, disasters triggered by natural hazards have resulted in more than 400,000 deaths, 397 million affected population, and $\$ 133$ billion direct physical losses in developing countries in Southeast Asia (Figure 1). ${ }^{2}$ The effects can be seen in damage to physical assets (i.e., housing, roads, water supply, and energy, among others) and losses (change in economic flow) incurred by physical assets. The impacts of disasters, such as loss of livelihoods and damage to assets, are often felt the most by the poor and vulnerable population with consequences to their long-term well-being. Southeast Asia remains home to an estimated 36 million people living below the international poverty line, about $5 \%$ of the global total. If efforts to achieve the SDGs in Southeast Asia are to succeed, undertaking disaster risk-informed development is no longer a choice but a necessity.

\section{Disaster risk is increasing with climate change and rapid unplanned socioeconomic development.}

Estimates show that developing countries in Southeast Asia suffer average annual losses ranging from \$213 million in the Lao People's Democratic Republic (Lao PDR) to $\$ 9.2$ billion in Indonesia from natural hazards (Table 1). These losses are set to increase due to three reasons. Firstly, climate change is changing the pattern of extreme weather events, i.e., the region faces more intense cyclones and frequent flooding. Secondly, exposure of people and assets to disasters are increasing as countries rapidly grow in an unplanned manner and investments are made with inadequate hazard considerations. Lastly, increase in losses will be due to vulnerabilities linked to wider socioeconomic challenges, such as rising inequality in many countries,

1 In this document, developing countries refer to ADB's developing members in Southeast Asia namely Cambodia, Indonesia, Myanmar, the Lao People's Democratic Republic, the Philippines, Thailand, and Viet Nam.

2 Data from EM-DAT: The Emergency Events Database - Université Catholique de Louvain (UCL) - CRED, D. Guha-Sapir www.emdat.be, Brussels, Belgium for period 1988-2017.

3 United Nations Development Programme and Association of Southeast Asian Nations. 2017. Financing the Sustainable Development Goals in ASEAN: Strengthening Integrated National Financing Frameworks to Deliver the 2030 Agenda. Bangkok.

Figure 1. Disaster Impacts in Southeast Asia (1988-2017)

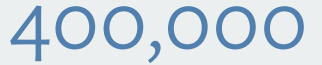

deaths

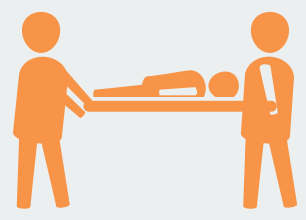

Source: Asian Development Bank

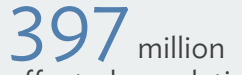

affected population

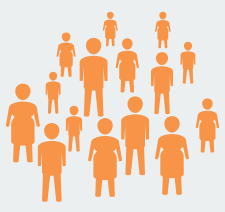

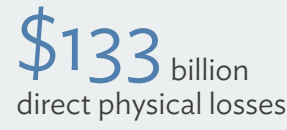

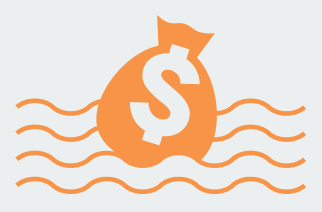


Table 1. Average Annual Losses in ADB Developing Member Countries in Southeast Asia

\begin{tabular}{lcc}
\hline \multicolumn{1}{c}{ Country } & Average Annual Losses (\$ million) $)^{\bar{a}}$ & \% of Gross Domestic Product (2017) \\
\hline Cambodia & 242.44 & 1.3 \\
Indonesia & $9,218.69$ & 0.8 \\
Lao People's Democratic Republic & 213.00 & 1.8 \\
Myanmar & $2,030.22$ & 2.6 \\
Philippines & $8,411.52$ & 2.8 \\
Thailand & $2,323.03$ & 0.5 \\
Viet Nam & $2,333.50$ & 1.3 \\
Source: & United Nations International Strategy for Disaster Reduction. 2017. Global Risk Assessment. Geneva.
\end{tabular}

social disparities, demographic changes with several countries aging fast, and weak institutions. If concerted actions are not taken to manage disaster risk in the context of wider development, the increasing losses will diminish previous achievements in development and put the future of the region at risk.

\section{Decision making for new investments can lock in levels of disaster risk for decades to come.}

Estimates show that infrastructure needs in developing Asia and the Pacific is over $\$ 26$ trillion, or $\$ 1.7$ trillion per year over 15 years from 2016 to 2030, if the region is to maintain growth momentum and respond to the pressing global challenge of climate change. In Southeast Asia alone, \$3.1 billion (equivalent to 5.7\% of gross domestic product (GDP)) is estimated to be required for infrastructure investment. ${ }^{4}$ This provides a huge opportunity as decisions to be undertaken for selecting, prioritizing, planning, designing, and maintaining new infrastructure can be made risk- sensitive thereby playing a vital role in ensuring rising levels of disaster risk are not locked in for decades to come. Examples may include political commitment to prioritize financing for integrated flood risk management measures, as part of annual public investment plans; projects that limit the exposure of road infrastructure in flood-prone areas by proposing new road alignment; investment that ensures design of power supply system in coastal areas factors in wind load from tropical cyclones; policies that incentivizes the construction of earthquake-resistant schools in areas of high seismic risk; and decisions to purchase disaster insurance for public buildings.

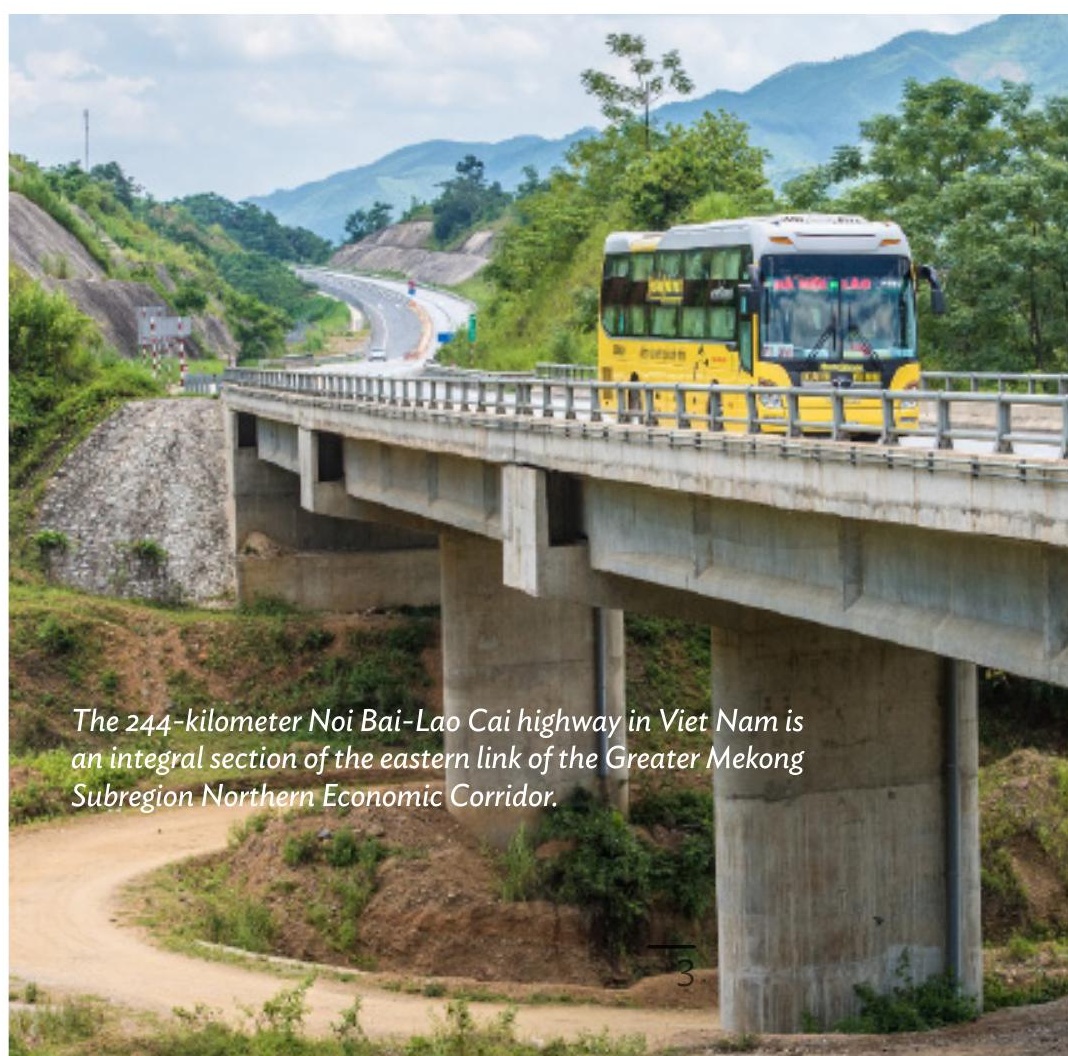




\section{ENHANCING UNDERSTANDING OF DISASTER RISK}

The processes (and associated guidelines and tools) used for public investment planning-plan formulation, identification of project concepts, prioritization of project proposals, appraisal of projects using various tools, project design, project implementation, and monitoring of projects-provide opportunities for factoring in disaster risk information thereby incentivizing investments to strengthen resilience. Sound knowledge of disaster risk is critical for this undertaking. The officials involved in public investment planning, such as officials in national agencies responsible for planning and finance and/or in planning departments of line agencies, need to engage actively in understanding disaster risk. Such understanding will help them in determining acceptable levels of risk and their appropriate management using a combination of measures to (i) reduce risk to acceptable levels through structural and nonstructural investments; and (ii) manage the residual risk through disaster preparedness measures, including actions to avoid loss of life (e.g., early warning) and ensure adequate and timely financing arrangements for disaster relief, early recovery and reconstruction (e.g., disaster reserves, contingency budget, and insurance) (Figure 2). The following $\mathbf{1 0}$ considerations become central in enhancing understanding of disaster risk among public investment planners, and their engagement in the disaster risk assessment process.

1 Understand disaster risk. Recognizing disaster risk as a function of three dynamic factors-hazards, exposure, and vulnerability-is vital in managing such risk

Disaster risk is a function of the probability of occurrence of a hazard of varying severity in a particular location, the people and assets situated in that location and therefore exposed to the hazard, and the level of vulnerability of those people and assets to that hazard (Figure 3). ${ }^{5}$ Understanding this inter-relationships between hazards, on the one hand,

5 ADB. 2014. Operational Plan for Integrated Disaster Risk Management. Manila.

Figure 2. Investments to Manage Disaster Risk
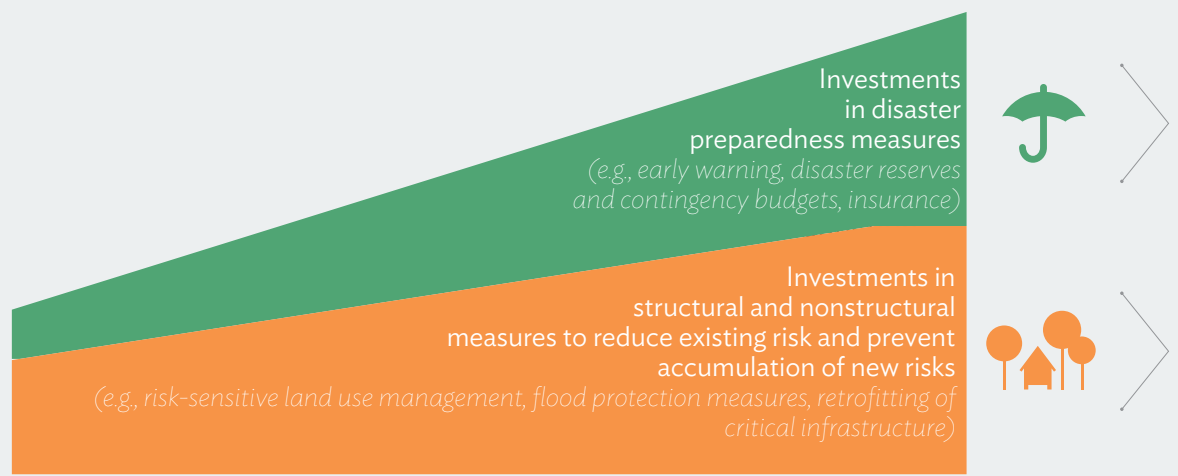

Investments in

residual risk management

Low risk

High risk

Investments in disaster risk reduction 
Figure 3. Components of Disaster Risk

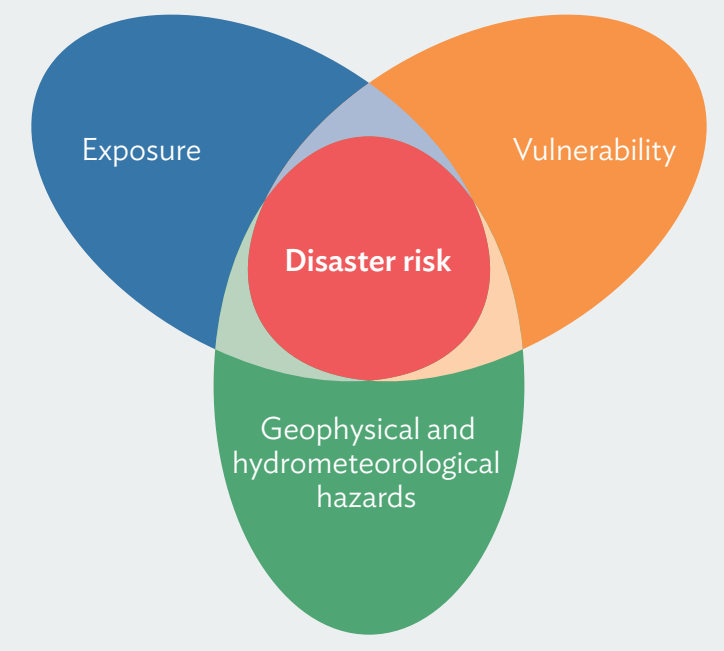

Source: Asian Development Bank

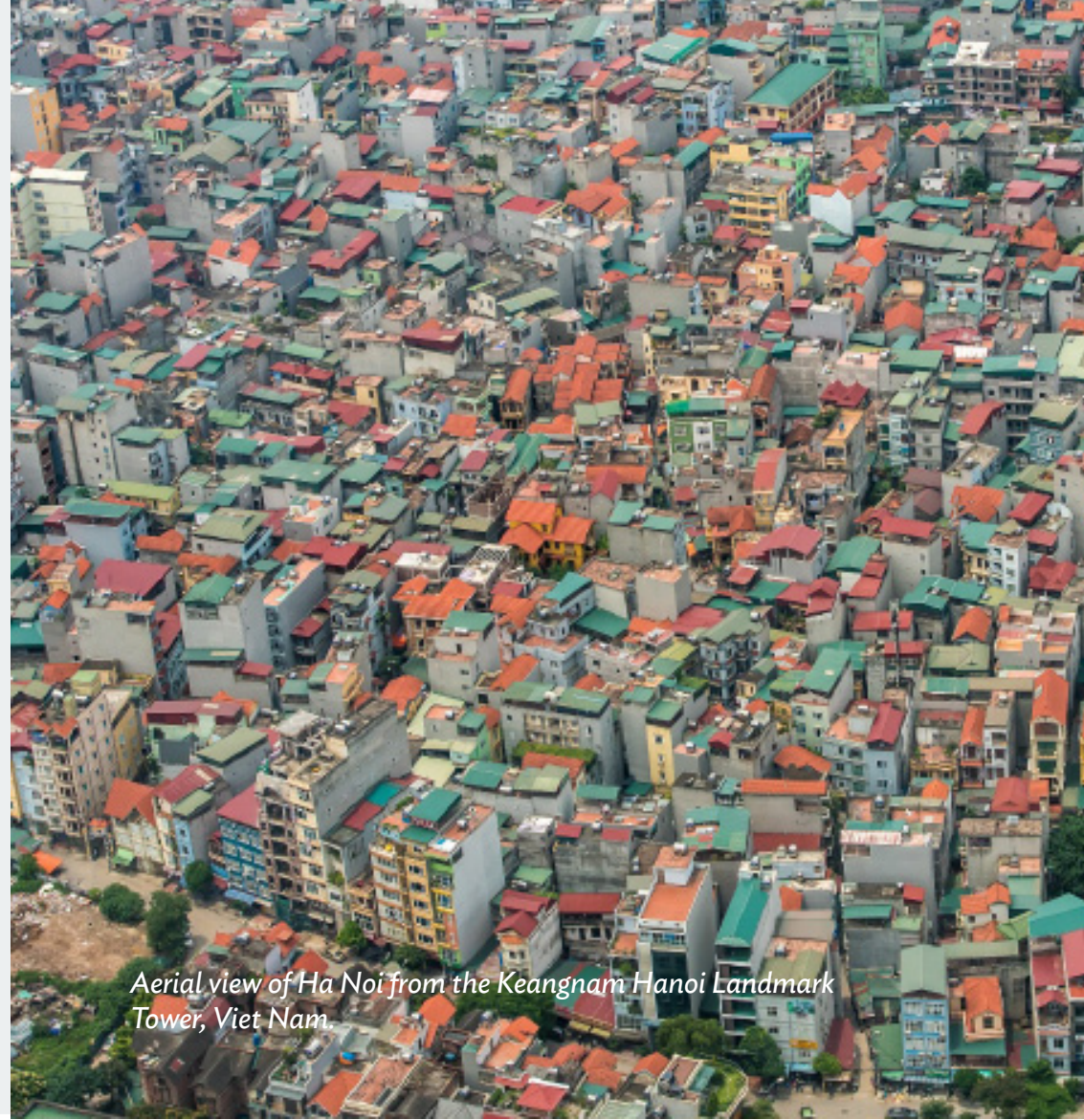

and the exposure and vulnerability of the population, buildings, livelihoods, and infrastructure, on the other, is important for public investment planners. It provides critical knowledge for use in decisions that reduce disaster risk of exposed population and assets in the present, and avoid the creation of disaster risk in the future. Thus, while hazards cannot be prevented, risk can be managed with a focused attention to limiting exposure and reducing vulnerability.

For example, an understanding of the characteristics of flood hazards (i.e., location, intensity, and frequency) in and around a city and how they interact with current and future exposure and vulnerability of people and assets enables the city planning office to adopt land use policy that steers new development away from floodplains, restricts the use of wetlands and unstable slopes through development control regulations, informs the preparation of storm water drainage plans, and prioritizes investments in flood embankments and flood early warning systems. Similarly, an understanding of changing hazard patterns due to climate change will help the planning office of the ministry of agriculture to understand how hazards such as floods, drought, and tropical cyclones can potentially impact agriculture in the future, and accordingly the type of investments needed to climateproof agriculture, i.e., crop diversification, increasing resilience of agriculture infrastructure, expanding skills of farmers, and improving access to market.

The three components of disaster risk are not static. It is expected that with climate change, hazard patterns will change resulting in more intense and frequent extreme weather events. Exposure levels, particularly in rapidly growing urban areas, are changing. Vulnerability is also changing with growing inequality and other factors. Furthermore, there are uncertainties associated with imperfect knowledge of the physical environment and the methodologies used in estimating the changes in each of the three components (see consideration 4). Thus, while information on historical disaster events can explain the past, understanding of risk should recognize the temporal and spatial changes in hazard, exposure, and vulnerability over time along with the uncertainties and the complex interdependencies between them, and accordingly estimate the probabilities of a full range of disaster events that might occur over a time frame of thousands of years, with all possible hazard scenarios, their likelihoods and potential impacts (see consideration 3). For public investment planners, this understanding of the full range of possible outcomes 
and their likelihood of occurrence becomes critical for determining public policy and setting funding levels for investments to reduce and accept risk.

\section{Inform purposefully. Disaster risk information should be appropriate to its intended use, articulated clearly and timely to guide decision making}

Disaster risk information provides analysis on the potential adverse impacts of natural hazards. Such information can be expressed in terms of geographical location of risk, affected population, damage to assets, and monetary losses and is beneficial for a range of public investment-related decision making. For example, officials working in the department of planning of the ministry of education may want to identify public schools that are at high risk to earthquakes, and a city planning officer may need to assess the fiscal risk the city faces from tropical cyclones. However, from the two examples above, the type of disaster risk information needed and the metrics to be used for communicating the information are different and should guide the scope and resources needed for undertaking disaster risk assessment. In the case of the first example, an interactive tool providing geospatial information on location and vulnerability of exposed public schools to varying intensities of earthquake may be useful, whereas for the latter, it will be critical to express the fiscal risk (in United States dollar terms) suffered by the city government in terms of annual average losses and probable maximum losses from tropical cyclones and associated city government contingent liability.

The timescale for the intended use of disaster risk information is related to the timescale for decision making purposes, will shape the type of risk information needed. For example, in the case of agriculture, information on seasonal forecasts and historical climate variability is important to inform annual crop planning, whereas understanding of long-term trends in climate will be critical for longer-term infrastructure planning such as irrigation structures.

The geographical scale of decision making is another important factor determining the nature of disaster risk information required. Disaster risk information at the national scale can guide decisions on where to invest, in which sector, and how to allocate funding. Disaster risk information at the local scale can help identify assets that are exposed to different hazards and subsequently draw up an investment program to retrofit the assets, undertake cost benefit analysis of different resilience measures, and select cost-effective investments.

Thus, clear articulation of the type of decisions to be made by public investment planners using disaster risk information becomes a critical starting point. Engagement of public investment planners with national and local institutions that have the mandate and capacity to produce disaster risk information (such as hydrometeorological agencies, geological surveys, DRM agencies, and universities) is necessary to convey needs, agree on the scope (geographical, resolution) of risk assessment required to meet those needs, and to be aware of the limitations in using the results of disaster risk assessment.

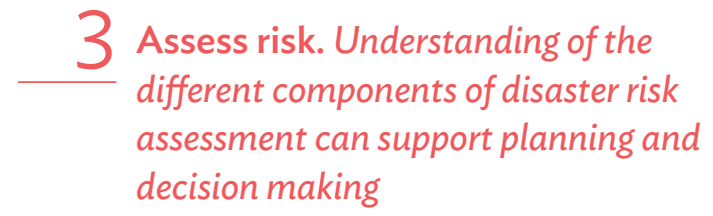

Disaster risk assessment comprises three input components: hazard, exposure, and vulnerability, resulting in determination of losses as the output of the assessment. While actual assessments will most likely be led by national agencies involved in generating hazard information or wider DRM with the technical support of universities and consultants, it is important for public investment planners to have a good understanding of each of the components as they are critical for a wide range of decision making, from spatial planning to project planning to fiscal planning (see Figure 4).

Firstly, the hazard component considers the hazard environment, covering the full range of types of natural hazard that could occur and their characteristics, disaggregated to a level in accordance with the required decision making. For example, wind data from tropical cyclone assessment is critical for designing infrastructure 

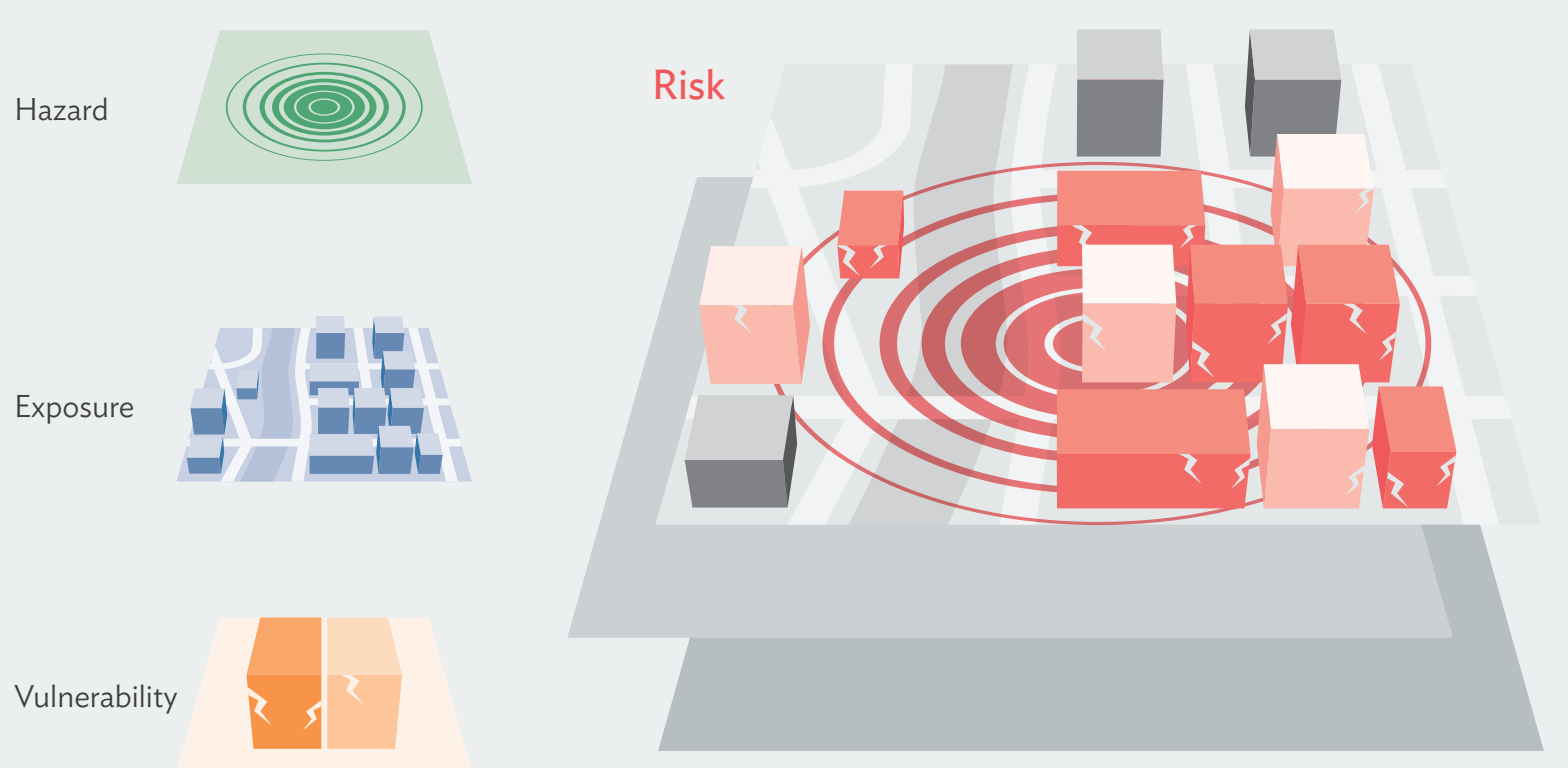

Source: $\quad$ Asian Development Bank

in coastal areas, while storm surge-related inundation data from tropical cyclone assessments is needed to inform land use zoning ordinances of coastal areas. Secondly, the exposure component would typically comprise datasets containing information on location and attributes (i.e., construction material, occupancy, height, structure, and age) of different assets, and their replacement costs. The exposure data, if disaggregated to the lowest possible spatial level, can help, for instance, identify the nature and scale of assets in hazard-prone areas that would need investments in retrofitting. Thirdly, the vulnerability component covers information on structural performance of assets in the event of different types of natural hazards with varying intensity. Typically, vulnerability functions are generated for each asset class, including different types of infrastructure and crops, to estimate the consequences of a variety of phenomena. Such information can support policy measures and investments, for example, to construct, retrofit, and maintain public assets, including through improved enforcement of building codes. Finally, the hazard, exposure and vulnerability data are combined to generate impact of loss data, including estimates of average annual losses by asset type, providing information which can help prioritize investments for DRM, including measures to reduce risk and strengthen residual risk management.

\section{Highlight assessment limits. Articulating the scope and limitations of disaster risk assessments can inform decision making}

Engagement in determining the scope of the disaster risk assessment will allow public investment planners to be aware of the limitations of the assessment that could restrict the use of the results. For example, the loss output may not have modeled the losses arising from secondary hazards such as tsunamis resulting from earthquakes, thereby resulting in differences between modeled losses versus actual losses (Box 1). Similarly, there may be limitations in the models used to develop hazard scenarios (e.g., limitations due to the size of data that can be used to run a model efficiently), which may limit their usage to a specific scale of decision making. 
Secondly, limitations are due to the uncertainties associated with climate information, which stems from the natural variability inherent in the climate system and from limitations in our ability to model the climate system for specific locations, especially for precipitation and extreme weather events, which are critical for disaster risk information. Officials involved in public investment planning should understand such uncertainties to ensure that these are reflected in decision making by adopting a set of risk management actions that meet the needs presented by a range of plausible futures.
Thirdly, information on hazard, exposure, and vulnerability is often scarce in developing countries, especially at a scale that can be used for public investment planning. A mechanism for the systematic collection and updating of disaster risk information from different sectors and at national and sub-national levels can improve reporting and use of information for disaster risk assessment.

Discussions with hazard specialists and officials from line agencies who are involved in maintaining exposure and vulnerability information can help in understanding these limitations beforehand, consequently defining the scope and application of disaster risk assessment.

Box 1. Flood Risk Assessment in Mawlamyine, Myanmar

Mawlamyine is the capital of Mon State in Myanmar. It is the fourth largest city in the country and the main trading center and seaport in southeastern Myanmar. The Department of Urban and Housing Development (DUHD) prepared an urban development plan for Mawlamyine in 2013. The plan highlights the area in the northeast of the city as susceptible to flooding after intensive rainfall due to a combination of topography and problems with the drainage network. Flood modeling for Mawlamyine has been carried out by various agencies and ranges from a local model for the Ataran river catchment to global flood models. The spatial coverage, underlying data, and model resolution vary for each model and are reflected in the modeling results. Comparisons were made for the 100-year flood extent maps from various models with a composite satellite image for the 2008,2013 , and 2015 floods, which were the worst flood events in recent years. The 2008 event was associated with Cyclone Nargis and primarily affected the coastal areas of Mawlamyine. The 2013 and 2015 events led to widespread fluvial flooding.

While the models provided useful information on wards affected by fluvial flooding, none of the models adequately replicated the coastal flooding experienced in 2008. None of the models also incorporated the urban drainage network in Mawlamyine and consequently, flood risk due to intense storms in urban areas could not be accurately modeled. Additionally, tidal surge effects have not been simulated and there may be additional flood risk, particularly in coastal areas. Climate change scenarios have not been modeled as well. Data on flood velocity were not available for any of the flood model simulations. Such modeling parameters and boundary conditions used in the modeling need to be clearly understood by DUHD and the city government, and considered when interpreting the results. Any inferences drawn from the modeling result should be treated with caution and refined when additional data becomes available.

Source: $\quad$ Asian Development Bank 
Demand quality data. Recognize that the quality of disaster risk information partly depends on the type of information provided by officials involved in public investment planning

The degree of effectiveness of the results of disaster risk assessment directly depends on data quality. The responsibility of generating, updating, and maintaining exposure-related and vulnerability-related data often lies with offices involved in public investment planning, namely ministries of planning, finance, and line agencies. For example, information on location, design, and quality of dike network in low-lying coastal areas is typically maintained by the department of irrigation or coastal works and is a critical input for national hydrometeorological agencies in modeling flood hazard.

While exposure datasets at an aggregate level can be generated statistically by disaster risk models, georeferenced information on characteristics of individual assets maintained by respective line agencies (such as schools, health facilities, and public buildings, among others) is critical for decision making to retrofit or replace assets. Thus, establishing and managing central public asset inventory databases, that apart from providing complete information on location, type, and ownership of all individual public assets, can also include information on hazard exposure, past disaster impact (see consideration 6), insurance status, and replacement value of each asset, is important. It is equally important to maintain information on state of repair of infrastructure, details on maintenance routines etc., which will give an indication on vulnerability of the asset. Public investment planners involved in setting up public asset inventory databases should ensure exposure and vulnerability related data is systematically captured.

Advancements in technology, such as the use of earth-observation data, open-source mapping, and mobile applications, have made it easier to collect and update building-by-building information of assets, and especially becomes important for areas where exposure is rapidly changing.

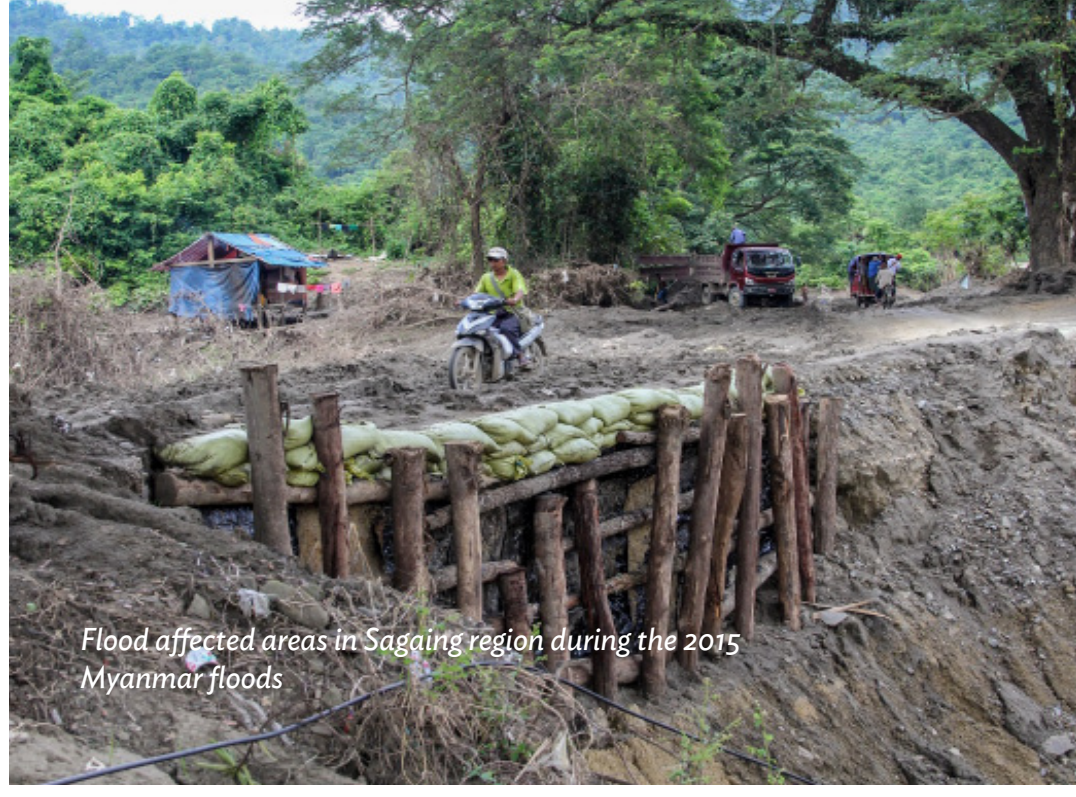

Document disaster losses. Collect disaster impact data to make losses visible

Linked to public asset inventory is the need to ensure that public investment planning processes of different line agencies systematically collect data on the impact of disasters on public assets. Such data should include type of hazards (primary or secondary), damage and losses in monetary terms, and descriptions of the nature of damage incurred by the asset. Systematic collection of disaster loss data over time can help shed light on risk patterns, provide a better understanding of the effectiveness of long-term investments to reduce disaster risk, and inform the annual planning process through improved maintenance of assets located in hazard prone areas.

In recent years, many countries in Southeast Asia have developed online databases to collect data on effects (damage and losses) of both severe and small and recurring disasters. However, due to limited capacity and resources, the databases are often not updated and specifically lack data on losses suffered by different sectors, in particular the private sector beyond housing. Typically housed in national DRM agencies, the linkage between these databases and wider sector asset management databases and data collected by central statistical agencies is weak and needs significant improvement (Box 2). Moreover, the usage of such databases to inform planning, including annual maintenance-related planning in different sectors, requires strengthening. 
Box 2. The Cambodia Disaster Loss and Damage Information System

Cambodia's National Committee for Disaster Management (NCDM) has established an online information system called the Cambodia Disaster Loss and Damage Information System (CamDi), to systematically collect, store, and analyze the impact of past disaster events, including small-scale events. The system includes data on road damage, among others. Roads are considered as critical for economic development in Cambodia. The Ministry of Public Works and Transport (MPWT) is responsible for planning, construction, and management of expressways, national and provincial roads, and urban roads, and the Ministry of Rural Development (MRD) is responsible for rural roads. The country's Road Law specifies that roads shall be appropriately maintained upon completion of construction work following technical regulations and maintenance procedures. Road maintenance in Cambodia has three classifications: (i) periodic maintenance (repairing damage after it has occurred); (ii) routine maintenance (repairing roads in anticipation of damage); and (iii) emergency repair (repairing severely damaged roads following disasters, to continue functioning, without upgrading the road).

The last few years have witnessed a significant increase in length of road infrastructure in the country. However, the road sector has been significantly impacted by extreme weather events. Experience has shown that the budget available for repair and rehabilitation of affected roads is never enough, thus often resulting in repair of only priority sections of damaged roads. MPWT and MRD have recognized that CamDi can be very useful in identifying geographical areas that are regularly affected by floods, based on historical damage data. Such information can help in priority setting, planning, and decision making for road repair and rehabilitation. Analytical tools, such as the seasonal and thematic map of CamDi, can demonstrate when and where roads are typically affected by natural hazards, which can support national and sub-national governments to improve preparedness, for example, by installing road information boards, preparing sandbanks to act as road embankments, and informing routine maintenance budget utilization. Historical data on location and kilometer of road submerged, damaged, and destroyed can provide an understanding of the trend for different geographical areas and inform road upgrade programs appropriately.

Recognizing this, road-related data fields in CamDi was updated and harmonized with the data requirements of MRD and MPWT's road inventory systems and their data reporting processes on road damage. It is expected that moving forward, such close alignment of CamDi with the road inventory system will facilitate easy collection and exchange of data between MRD, MPWT, and NCDM.

\section{7} Follow the funds. Track public expenditure on disaster risk management

Most governments in Southeast Asia have adopted DRM-related policies and strategies. However, it is not clear on how much government spending can be linked to DRM. Such investments are often scattered across several sector budgets and, in some cases, may form just one component or even an indirect benefit of a wider development project, rather than a standalone project. As such, the extent of public investment in DRM may not be explicitly reflected in records on the allocation and use of public funds, and the issue of DRM is possibly not even fully considered in national budgetary processes. There are additional issues in monitoring expenditure on post-disaster relief, and early recovery and reconstruction, reflecting significant reliance on post-disaster reallocations of financial resources which are poorly recorded.

Public investment planners should encourage relevant colleagues in their departments/agencies to adopt methodologies to track public expenditure on DRM (Box 3). This would allow them to (i) hold public bodies to account for DRM-related policy and spending commitments; (ii) ensure that individual line agencies have sufficient resources to meet their DRM-related responsibilities; (iii) ensure that the balance of expenditure between disaster risk reduction and post-disaster response is cost-effective; and (iv) ensure that the extent and nature of public spending on DRM is rational relative to the scale and nature of disaster risk and other demands on public resources. 


\section{Box 3. Disaster Risk Management Public Expenditure and Institutional Review in the Lao People's Democratic Republic}

The Lao People's Democratic Republic (Lao PDR) is identified as highly at risk to hazards, such as river and urban flooding, typhoons, landslides, and wildfires. Expenditure on disaster risk management (DRM), however, is not clearly identified or linked to specific DRM objectives under the present planning and budgeting system in the Lao PDR. While many DRM-relevant projects might also be categorized as climate change adaptation relevant investments, there are other areas of both recurrent and investment expenditure that implicitly contribute to DRM. The current budget process does not clearly identify these projects or expenditure items to enable clear and specific tracking of DRM spending.

Recognizing these limitations, the Government of the Lao PDR undertook an exercise to track DRM-related public expenditure for fiscal years 2010-2011 through 2013-2014. Public expenditure was classified at two levels. At the first level, expenditure comprised five categories having very high, high, mid, low, minor or no relevance to DRM outcomes. The decision on which classification should be applied to each discrete expenditure line was determined based on review of budget lines and, project documents, local knowledge and research on how similar projects and programs may have been classified, and consultations with implementing agencies. Varying weights ranging from o for no DRM relevance to 100 for full DRM relevance were applied to expenditure under each of the five categories to provide an estimate of total DRM-relevant spending. The level 2 classification captured the nature of the expenditure and its purpose in relation to DRM. It was split into six categories under two principal heads: (i) pre-disaster interventions covering preparedness, prevention, and resilience; and (2) post-disaster relief, recovery, and reconstruction. Under the first principal heading, the categories covered policy and institutional development; governance, capacity building and advocacy; research and early warning systems; and investments for disaster risk reduction. Under the second principal heading, the categories covered disaster response expenditure and recovery/reconstruction.

Over the four fiscal-years 2010/11-2013/14, it was estimated that DRM-related expenditure, on average, accounted for $5.6 \%$ of total combined ministry and provincial budgets, comprising an estimated $7.1 \%$ of total ministry expenditure and $2.1 \%$ of provincial expenditure. These amounts were equivalent to an estimated $1.9 \%$ of GDP, comprising $1.7 \%$ and $0.2 \%$ of GDP for ministries and provinces respectively. Expenditure on post-disaster needs may have been attributable in part to disasters occurring before the period of analysis. This appears to have been the case for 2010/11 where expenditure on post-disaster relief and recovery was reported as high despite no disaster occurrence in that year.

Analysis at the national level indicated that the agencies with the largest estimated value of DRM-relevant expenditure were the Ministry of Public Works and Transport (MPWT) at 46.4\% of all DRM-relevant expenditure over the four years; Ministry of Agriculture (MAF) at $18.4 \%$; organizations and provincial administration at $12.1 \%$; and Ministry of Labour and Social Welfare at 6.1\%. At the provincial and/or local levels, the greatest proportion of DRM-relevant expenditure was incurred by Vientiane Capital (32.2\% of provincial DRM-relevant expenditure); Vientiane province (7.7\%) and Oudomxay (6.5\%). No other province contributed more than 5\% to total DRM-relevant expenditure.

Most of the DRM-related expenditure in the four-year period was incurred for capital expenditure, for example, road construction and maintenance and other infrastructure development projects, including irrigation and similar investments. These classifications accounted for about $88 \%$ of estimated total DRM-related expenditure. Postdisaster relief, recovery and reconstruction accounted for the balance of around $12 \%$ of the total.

The study provided the following recommendations to strengthen financial management systems for DRM: (i) provide more detailed budget line descriptions on outputs and expected outcomes in budget expenditure reports to enable comprehensive analysis of expenditure, including for DRM; (ii) ensure budget expenditure information is made available in a timely manner, especially for state budget revenue and expenditure implementation for each fiscal year, and for expenditure on State Reserve Fund, contingency and other DRM-related funds; (iii) introduce a budget tagging system into the budget cycle to enable DRM and other cross-cutting expenditure components to be identified for monitoring purposes; and (iv) develop and/or finalize standard operating procedures for all key agencies, the State Reserve Fund, and other DRM-related funds, to enhance DRM policy, planning, and budget allocations as well as efficient and transparent funding mechanisms for response and recovery activities.

Source: $\quad$ Asian Development Bank and United Nations Development Programme 


\section{Box 4. Impact of Typhoon Damrey on Agriculture in Viet Nam}

Typhoon Damrey (known in Viet Nam as Storm No. 12) made landfall in the early morning of 4 November 2017 affecting 15 provinces in the South Central and Central Highlands regions. Damrey is the strongest typhoon to strike Viet Nam since 2001. Khanh Hoa province suffered the most, with total economic losses worth $\$ 696$ million. The gusty winds resulted in wide-scale damage and losses in the agriculture sector including crop production, livestock, fishery, and aquaculture. The cultivated area with perennial crops, especially plantations (i.e., mango, banana, coconut, and cashew nuts, among others) was seriously affected. The damages in these plantations will continue to have an impact over several years, before the trees bear fruit again. The bulk in volume and value of the losses for annual crops corresponds to sugarcane and cassava. These losses are the result of the disaster timing, at the beginning of the winter-spring season after most of the spring-autumn rice crops have been harvested. Farmers had to wait for the water to recede from the flooded crop fields, which delayed the planting of winter and winter-spring season. It was estimated that, because of the typhoon, the GDP growth for Khanh Hoa province in 2018 would decline by $0.9 \%$ compared to baseline projection. The agriculture sector for the province is expected to contract by $2.6 \%$ from 2017 .

World Bank. 2017. Khanh Hoa Provincial Peoples' Committee. 2017 Viet Nam Post-Typhoon Damrey Rapid Damage and

8 Plan for recovery. Engage in postdisaster needs assessment processes

Post-disaster needs assessments are carried out to determine effects (damage and losses) and secondary impacts of disasters, and to estimate the financial needs for recovery and reconstruction. Assessments include estimation of damage to stock (e.g., kilometers of road damaged) and changes in economic flows (e.g., loss in toll revenue due to road damage). The damage to stock can help identify the underlying factors that has resulted in the damage, thereby guiding reconstruction using principles of "building back better" and informing the construction of new assets. The change in economic flows arising from damaged assets and estimation of time needed for undertaking recovery and reconstruction can help inform strategies to enhance financial preparedness for potential disaster events (Box 4).

Public investment planners should be engaged in postdisaster needs assessment processes by providing baseline information on sector performance (without disaster), assessing disaster effects to understand how the sector will perform (with disaster); and identifying policy measures needed to undertake recovery and reconstruction.

\section{Tap local institutions. Ensure disaster risk assessments are credible, locally led and enhance local capacity}

If disaster risk assessments are to inform public policy and influence allocation of financial resources, they need to be credible, based on robust scientific approach, and grounded on local realities. Currently, disaster risk assessments are largely implemented by consultants where interaction with government agencies and local technical organizations are usually limited to collection of data and submission of assessment results. While such an approach provides opportunities to learn from global practices (where the consultants have been involved in the past), they are not sustainable since the engagement of local stakeholders are limited. This results to assessment findings being seldom used and the assessments almost never updated.

Disaster risk assessment is not a one-off exercise, and longer-term in-country/local capacity is needed to update such assessments regularly. Moving forward, there is an urgent need to include local technical organizations, such as universities, in leading disaster risk assessment processes. Faculties involved in environmental sciences, geography, water resources, and structural engineering, among others, should be capacitated to lead disaster risk assessments, and guide masters and $\mathrm{PhD}$ students in undertaking research. 
Such approach will ensure that assessments, while scientifically robust, capture local characteristics (e.g., develop flood vulnerability functions for buildings based on local typology of buildings), build local ownership, and contributes to longer-term sustainability and capacity. Involvement of well-known national and local technical experts will enhance credibility, thereby increasing the chances of the results being taken up by decision-makers. Even if the task of undertaking an assessment is commissioned to external consultants, local technical agencies should be closely involved as they provide national insights and are able to interpret the findings in ways that can be understood by public investment planners and other stakeholders starting from the scoping stage to ensure that the assessment can build on past initiatives and can be updated by relevant national agencies when necessary. Public investment planners should play an active role in advocating for the involvement of local technical agencies in undertaking disaster risk assessments.
10 Establish interagency links. Strengthen institutional arrangements to systematically lead disaster risk assessment

National legislation governing DRM in most Southeast Asian countries highlight the need for undertaking disaster risk assessments. However, the process for undertaking such assessments is as critical as the final output. The process requires close coordination between different agencies (for reasons explained in earlier considerations) involved in DRM, climate change adaptation, hydrometeorological and geological institutes, line agencies, and focal agencies for planning and finance. It is important that such coordination mechanisms are institutionalized at the national and local level, especially to ensure common definitions, and reporting and file formats (i.e., formats in which data is saved) are used between agencies; systematic updating of assessments; and most importantly, uptake of the results of the assessments for public investmentrelated decision making (Box 5). Public investment planners should proactively strengthen such linkages between agencies.

Box 5. Disaster Risk Assessment in the Myanmar Action Plan for Disaster Risk Reduction 2017

The Myanmar Action Plan for Disaster Risk Reduction (MAPDRR) 2017 has identified 32 priority actions under four pillars, including a pillar on "assessing disaster and extreme event risk and creating public awareness on disaster risk reduction." The first priority action under this pillar is "establishment of central coordination mechanism and repository of disaster risk information in Myanmar" under the leadership of the Department of Meteorology and Hydrology and with all relevant departments. The objectives of the coordination mechanism are to (i) create a central repository of all disaster risk information and related data in Myanmar; (ii) catalogue disaster risk assessment methodologies and increase compatibility of data/outputs; and (iii) promote wider dissemination and usage of disaster risk information. The indicative activities include:

Setting up a disaster risk assessment committee/group and its working mechanism

Cataloguing of standard disaster risk assessment methodologies for enhanced compatibility of data and risk assessment outputs

Capacity building on disaster risk assessment, especially updating existing risk information

A database / repository of disaster risk assessment outputs and data

System for easy access of disaster risk information and exchange of data among departments

Actions toward wider usage of disaster risk information

The government is taking steps to set up the central coordination mechanism and has initiated undertaking national level flood and cyclone risk modeling. 


\section{CONCLUSION}

Disaster losses are rising with the increasing pace of development in Southeast Asia. Officials involved in public investment planning recognize that if efforts to achieve the SDGs are to have long-term sustainable impacts, increased public investments will be needed to reduce disaster risk, and improve planning and regulation to create a more favorable environment encouraging the private sector and communities to engage in risk reduction activities. Robust understanding of disaster risk, active engagement in risk assessment processes, fostered partnerships with relevant national technical agencies, and strengthened interagency linkages are the critical building blocks for undertaking risk-informed development. 



\section{Understanding Disaster Risk for Advancing Resilient Development}

Knowledge Note

This knowledge note highlights ten key considerations for enhancing the understanding of disaster risk among public investment planners. It is designed to aid their engagement in the disaster risk assessment process. If the sustainable development goals are to be achieved, it is necessary to integrate disaster risk consideration in the public investment planning processes. Government officials involved in public investment planning have a key role to play in defining the risk information-related needs and supporting the development of such information in close partnership with hydrometeorological and geological institutes and relevant national agencies that address disaster risk management and climate change adaptation.

\section{About the Asian Development Bank}

ADB is committed to achieving a prosperous, inclusive, resilient, and sustainable Asia and the Pacific, while sustaining its efforts to eradicate extreme poverty. Established in 1966, it is owned by 67 members -48 from the region. Its main instruments for helping its developing member countries are policy dialogue, loans, equity investments, guarantees, grants, and technical assistance. 